\title{
Simulating low and high streamflow driven by snowmelt in an insufficiently gauged alpine basin
}

\author{
Feiyun Zhang $\cdot$ Sajjad Ahmad $\cdot$ Hongqi Zhang $\cdot$ \\ Xin Zhao $\cdot$ Xianwei Feng $\cdot$ Lanhai Li
}

Published online: 23 January 2015

(c) Springer-Verlag Berlin Heidelberg 2015

\begin{abstract}
Snowmelt and water infiltration are two important processes of the hydrological cycle in alpine basins where snowmelt water is a main contributor of streamflow. In insufficiently gauged basins, hydrologic modeling is a useful approach to understand the runoff formation process and to simulate streamflow. In this study, an existing hydrologic model based on the principles of system dynamics was modified by using the effective cumulative temperature $\left(>0{ }^{\circ} \mathrm{C}\right)$ to calculate snowmelt rate, and the soil temperature to adjust the influence of the soil's physical state on water infiltration. This modified model was used to simulate streamflows in the Kaidu River basin from 1982 to 2002, including normal, high, and low flows categorized by the $\mathrm{Z}$ index. Sensitivity analyses, visual inspection, and statistical measures were employed to evaluate the capability of the model to simulate various components of the streamflow. Results showed that the modified model was robust, and able to simulate the three categories of flows well. The model's ability to reproduce
\end{abstract}

F. Zhang $\cdot$ X. Zhao $\cdot$ X. Feng $\cdot$ L. Li $(\bowtie)$

State Key Laboratory of Desert and Oasis Ecology, Xinjiang Institute of Ecology and Geography, Chinese Academy of Sciences, Urumqi 830011, China

e-mail: lilh@ms.xjb.ac.cn

F. Zhang

Graduate School, University of Chinese Academy of Sciences, Beijing 100049, China

S. Ahmad

Department of Civil and Environmental Engineering, University of Nevada, Las Vegas, NV 89154-4015, USA

H. Zhang

Key Laboratory of Land Surface Pattern and Simulation, Institute of Geographic Sciences and Natural Resources Research, Chinese Academy of Sciences, Beijing 100101, China streamflow in low-flow and normal-flow years was better than that in high-flow years. The model was also able to simulate the baseflow. Further, its ability to simulate spring-peak flow was much better than its ability to simulate the summer-peak flow. This study could provide useful information for water managers in determining water allocations as well as in managing water resources.

Keywords Streamflow - Cumulative temperature . Snowmelt · Infiltration · Kaidu River basin · System dynamics

\section{Introduction}

The growth in population and social-economic development worldwide resulted in an increased demand for water (Dawadi and Ahmad 2013; Qaiser et al. 2013; Wu et al. 2013; Shrestha et al. 2012). Climate change is influencing water supplies (Sagarika et al. 2014) through hydrologic extremes (Stephen et al. 2010; Puri et al. 2011; Li et al. 2014a), which could potentially result in the risk of flooding and drought. Floods resulting from high flows cause serious damage to water infrastructures such as reservoirs and channels (Forsee and Ahmad 2011) as well as to crops, property, and lives (Ahmad and Simonov 2001; Simonovic and Ahmad 2005; Mosquera-Machado and Ahmad 2007); while droughts caused by low flows can influence water supplies to industries and affect the ecological environment (Choubin et al. 2014). Hydrologists have been exploring various methods to assess water supplies (Huang et al. 2013; Kalra et al. 2013; Carrier et al. 2013) and meet water demands (Mirchi et al. 2012). However, water management in alpine basins differs from other regions, mainly because the spring streamflow is driven by snowmelt which 
primarily depends on temperature and precipitation. Temperature influences the forms of the precipitation in winter and the intensity of snowmelt in spring as well as the physical status of soil which can influence the infiltration rate of snowmelt water. Precipitation takes place as snowfall in winter and early spring, and water is stored temporarily as snowpack in the lower or middle alpine region (Kuusisto 1984; Blöschl et al. 1990; Micovic and Quick 1999). In large basins, the geographic conditions, physical environment, and water sources of rivers vary with the wide range in elevation. The water sources of rivers in alpine basins include water melt from snowpack and/or glaciers in the high-altitude mountains (Yang and Cui 2005), seasonal snowmelt in mid-range mountains, and rainfall in lowaltitude mountains (Xu et al. 2008). Seasonal snowmelt and rainfall often result in peak flows in both spring and summer (Jiang and Hu 2004). The peak flow driven by seasonal snowmelt that occurs between April and May (Shang et al. 2013) is known as spring snowmelt peak flow (SSPF); and the peak flow driven by the rainfall taking place between June and August (Jiang and Hu 2004) is known as summerpeak flow (SPF). Both the spring-snowmelt peak flow and summer-peak flow could cause serious damage. Hence, a better understanding as well as more accurate simulation and forecasting of peak flow could help provide information to prevent damage from flooding.

The meteorological and hydrological observation stations in Xinjiang, located in northwestern China, are scarce, especially in the higher elevation of the mountains, resulting in difficulties when studying the hydrological processes of the region. In order to better explain the runoff process, hydrological modeling is a useful approach to clarify the endogenous relationship between climatic factors and streamflow as well as the formation mechanism of the runoff. Various hydrological models have been used to simulate the runoff process. In the last few decades, system simulation models have contributed to great progress in the research and application of watershed hydrology. Based on the physical process of streamflow formation, the synthetic runoff model (Bobba and Lam 1990; Arp and Yin 1992; Kite 1998) and Xin'anjiang model (Zhao 1984; Zhang 1989) can effectively predict the runoff and its response to changes in the external variables in rainfall-dominated basins. Other hydrological models use snowmelt as a module in order to simulate streamflow resulting from both rainfall and snowmelt water. These include the Hydrological Simulation Program-Fortran (HSPF) model (Bicknell et al. 1997), the Precipitation-Runoff Modeling System (PRMS) (Leavesley et al. 1983), the Hydrological Simulation Model (HSM) (Manley 1978), the MIKE 11 model (Danish Hydraulic Institute 1992), the Semi-distributed Land Use-based Runoff Processes (SLURP) model (Kite 1998), the Hydrologiska Byrans Vattenbalansavdelning
(HBV) hydrology model (Lindström et al. 1997), and the Snowmelt Runoff Model (SRM) (Martinec et al. 1994). The SRM model and the Soil and Water Assessment Tool (SWAT) have been used to simulate streamflow that is contributed by snowmelt water and rainfall in the middle section of the Tianshan Mountains, China, using the degree-day factor method (Zhang et al. 2006; Dou et al. 2011; Yu et al. 2011; Ji and Luo 2013; Li et al. 2014b). In spring, when the daily mean temperature is less than $0{ }^{\circ} \mathrm{C}$, the maximum temperature in a day may be greater than $0{ }^{\circ} \mathrm{C}$, in which snowmelt can occur. In this case, the daily mean temperature may not reflect the effect on snowmelt when temperatures $>0{ }^{\circ} \mathrm{C}$ exist within 1 day ( $\mathrm{Yu}$ et al. 2013a). In order to reflect a diurnal variation of the daily temperature within the maximum and minimum bounds, Yu et al. (2013a) and Li et al. (2014b) suggested that a modified SRM model could be used to simulate the streamflow in spring more accurately by using the accumulated active temperature instead of daily average temperature to calculate the snowmelt rate. However, the modified SRM could not efficiently simulate the summer streamflow contributed by rainfall as accurately as the spring streamflow driven by a mixture of snowmelt and rainfall. The main reason is that SRM was designed for snowmelt runoff simulation. The SWAT model can simulate the runoff better in humid, semi-humid, and rainfallrich areas in the plains region; however, in arid and semiarid alpine regions where the streamflow is dominated by snowmelt in the spring, the simulated streamflow of the SWAT model underestimates the values ( $\mathrm{Yu}$ et al. 2013b).

Alpine regions commonly have seasonal frozen soil. During the snowmelt period, frozen soil prevents water infiltration and causes an increased runoff ratio (Shanley and Chalmers 1999). In cold regions, the influence of the frozen soil on water infiltration and percolation rates not only occurs in the surface soil layer, but also under the surface soil layer. However, most hydrological models rarely consider the influence of frozen soil on streamflow. $\mathrm{Li}$ and Simonovic (2002) applied the principles of system dynamics to develop a hydrological model that more accurately reflects the hydrological processes of the North American Prairies where rivers are contributed by snowmelt water and rainfall together. The capability of this model has been proven by Elshorbagy et al. (2005). The influence of the physical status of the surface-soil layer on water infiltration has been taken into consideration in the system dynamic model to better simulate the streamflow. However, the influence of the frozen status of subsurface soil layer on water infiltration and percolation remains unclear.

Snowmelt water fills into the snowpack rather than charge streamflow when snowpack exits; and when the maximum temperature is greater than $0{ }^{\circ} \mathrm{C}$ and the minimum temperature is less than $0{ }^{\circ} \mathrm{C}$ within a day in spring, part of the snowmelt water refreezes. The refrozen melt 
water and the liquid water in the snowpack cannot charge the streamflow. Only when the temperature reaches a certain point can the snowmelt water charge the streamflow effectively. Hence, the refreezing process of snowmelt water should be considered when calculating the contribution of the snowmelt water to streamflow.

In order to better estimate snowmelt rates and reflect the influence of the frozen status of soil, this study modified an existing system dynamics model to simulate the streamflow in an insufficiently gauged alpine watershed in Xinjiang, China. The modifications are: (1) using the daily effective $>0{ }^{\circ} \mathrm{C}$ cumulative temperature instead of daily mean temperature as the number of degree days in order to simulate the snowmelt rate; (2) using the soil temperature in different soil layers to reflect the soil's physical state in order to adjust the infiltration and percolation rates from the surface-soil layer to the subsurface soil layer and from the subsurface soil layer to the groundwater layer. The modified model was calibrated and validated by using historical streamflow events in the Kaidu River basin, which is an insufficiently gauged alpine basin in northwestern China. The observed streamflow during the study period was categorized into three categories of flows, i.e., normal flow, high flow, and low flow, based on the $\mathrm{Z}$ index method. The capabilities of the modified model to simulate these three categories of flows, including their characteristics, were evaluated in this study. This study could provide useful information for water managers in determining water allocations as well as in managing water resources.

\section{Study area}

The Kaidu River basin lies at the southern slope of the Central Tianshan Mountains, and spans $42^{\circ} 43^{\prime}-43^{\circ} 21^{\prime} \mathrm{N}$ and $82^{\circ} 58^{\prime}-86^{\circ} 05^{\prime} \mathrm{E}$, with a catchment area of about $22,000 \mathrm{~km}^{2}$ (Fig. 1). The Kaidu River originates from the Hargat Valley and the Jacsta Valley in the Sarming Mountain, and flows through the Yulduz Basin and the Yanqi Basin; it discharges into the Lake Bosten. The Sarming Mountain has the highest peak, 5,000 $\mathrm{m}$ above sea level (ABSL), and is located in the middle section of the Tianshan Mountains. Lake Bosten, the largest freshwater lake in Xinjiang, is the source of the Peacock River, which links to the Tarim River. Bayinbuluk Station (2458 m ABSL) is the only meteorological station with a long historical temperature and precipitation dataset, and Dashankou Station (1,400 m ABSL) is the only hydrological station with a long historical runoff dataset.

The study area is focused on the area above the Dashankou hydrological station because the precipitation below Dashankou station cannot generate an effective surface runoff; moreover, the runoff below Dashankou station is strongly influenced by human activities. The study area is
$18,725 \mathrm{~km}^{2}$, with an average elevation of $3,100 \mathrm{~m} \mathrm{ABSL}$ (Tao et al. 2007). The average annual temperature and the extreme minimum temperature in the study area are 4.6 and $-48.1^{\circ} \mathrm{C}$, respectively, based on observed data from Bayinbuluk station. The maximum annual snow depth is $12 \mathrm{~cm}$, and the annual snow-cover days are 139.3 days (Xu et al. 2008). The distribution of precipitation within a year is variable; however, precipitation as rainfall from June to September accounts for $60-80 \%$ of annual precipitation ( $\mathrm{Su}$ et al. 2007). With the change in climate, snowfall, precipitation, and the ratio of snowfall to precipitation have had increasing trends from 1961 to 2010 (Guo and Li 2014).

\section{Methodology}

\subsection{Modeling spring snowmelt and summer peak flow}

Based on the principles of system dynamics, $\mathrm{Li}$ and Simonovic (2002) developed a hydrological model for predicting floods dominated by snowmelt in watersheds of the North American Prairies. The model simulates runoff by means of a water balance in the vertical direction, using five tanks, i.e., snow storage, vegetation interception, water storage in the surface-soil layer and subsurface-soil layer, and groundwater layer (Fig. 2). The model can simulate the streamflow contributed by both snowmelt water and rainfall.

The original model defined 'snow storage' as the accumulation of snowfall minus snowmelt water. Interception of water by vegetation came from rainfall and snowmelt, and the vegetation interception water was lost due to evaporation from the vegetation cover. Water infiltration from overland flow generated by rainfall and/or snowmelt water contributed to the water storage in the surface-soil layer; and the water in the surface-soil layer was lost due to evapotranspiration, interflow, and percolation into the subsurface-soil layer. Water percolation from the surface-soil layer added to the subsurface-soil layer, and the water in the subsurface-soil layer drained by means of evapotranspiration, interflow, and percolation into the groundwater. The inflow to the groundwater layer came from water percolation from the subsurface soil layer, and outflow from the groundwater layer was a recharge to the streamflow by means of baseflow. Detailed information about water storage in the five tanks and the runoff calculation in a watershed can be found in $\mathrm{Li}$ and Simonovic (2002).

\subsection{Model modification}

\subsubsection{Estimate of the rate of snowmelt}

In the study by Li and Simonovic (2002), the daily mean temperature was used as the number of degree-days to 
Fig. 1 Location of the study area and stations

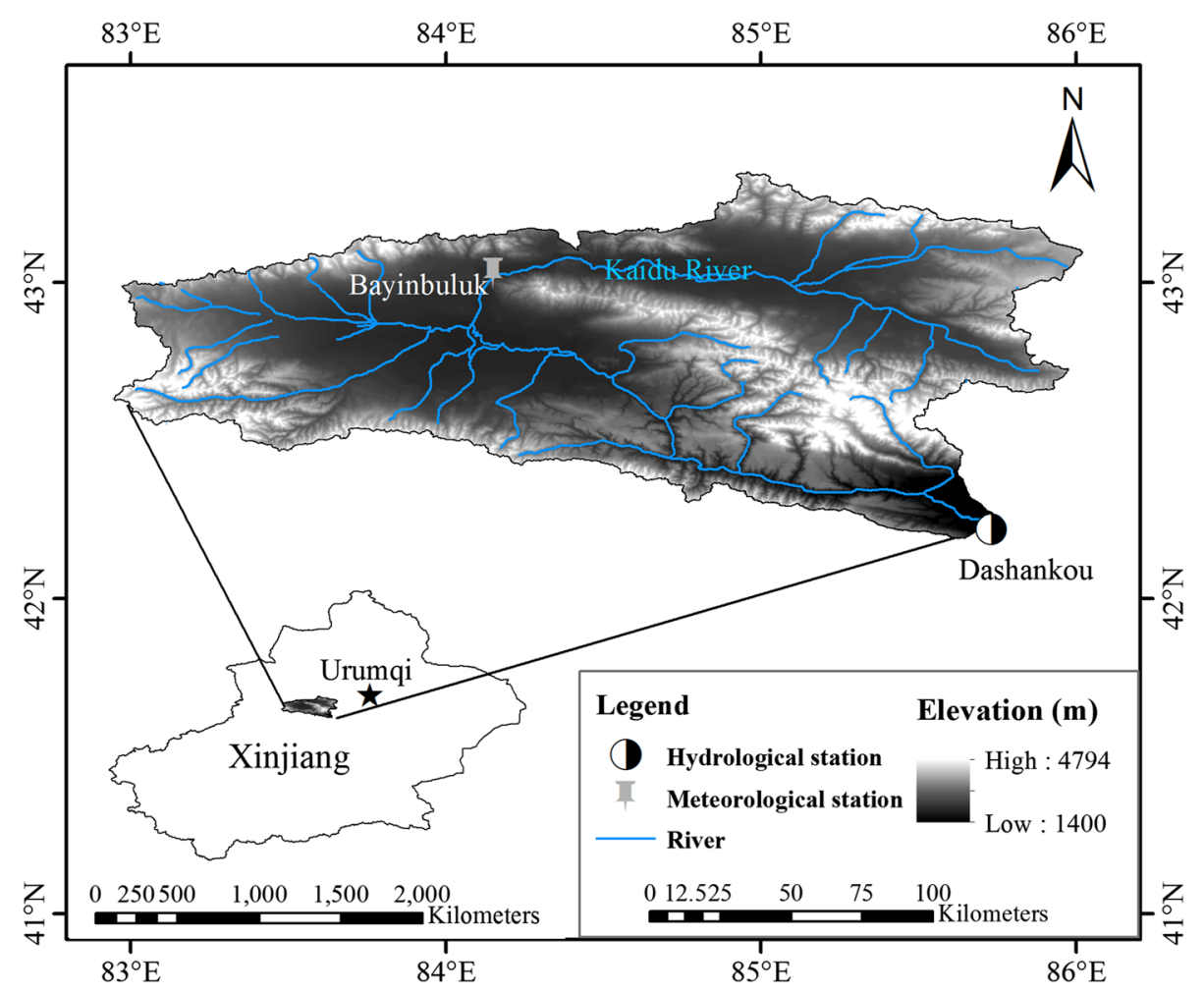

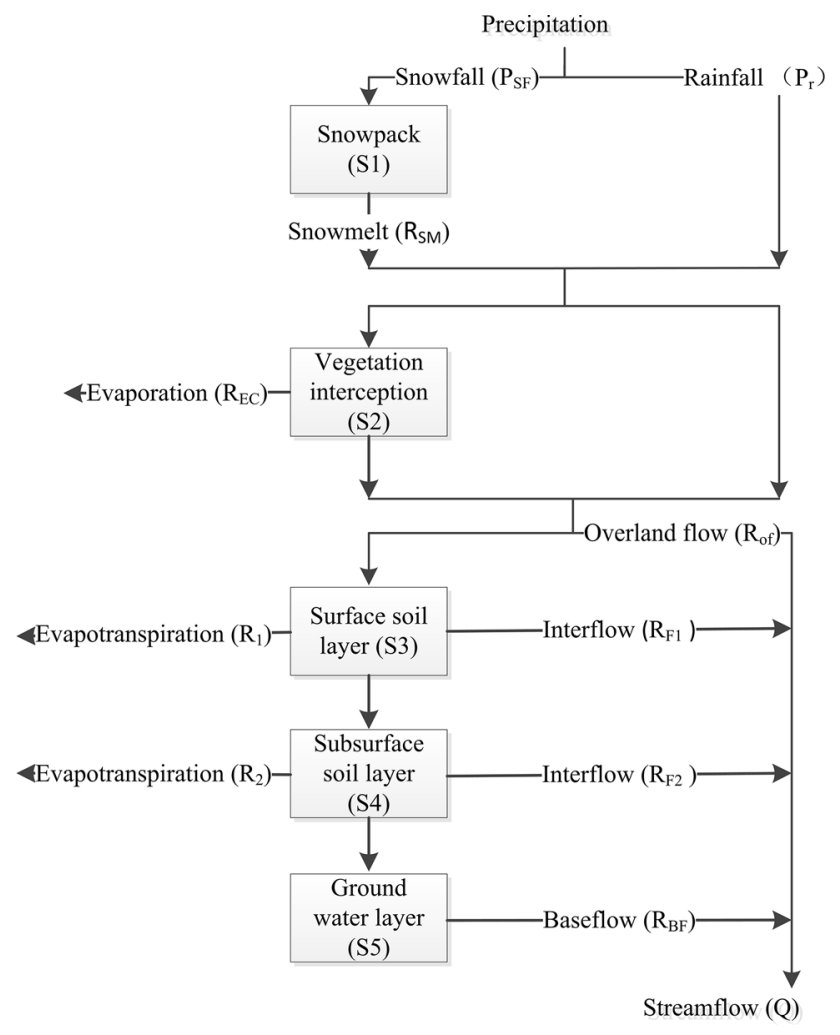

Fig. 2 The structure of the model for spring snowmelt and summer peak flow (Li and Simonovic 2002) estimate the snowmelt rate with the degree-day factor. However, daily temperatures experienced diurnal variations. Given a day in which the maximum temperature is greater than $0{ }^{\circ} \mathrm{C}$ and the minimum temperature is less than $0{ }^{\circ} \mathrm{C}$, if the maximum temperature is less than the absolute value of minimum temperature, the daily mean temperature may still be less than $0{ }^{\circ} \mathrm{C}$. This implies that the daily mean temperature may ignore the effect of temperatures greater than $0{ }^{\circ} \mathrm{C}$ within a day on snowmelt, assuming that the snowmelt takes place as the temperature is greater than $0{ }^{\circ} \mathrm{C}$. The average daily $>0{ }^{\circ} \mathrm{C}$ cumulative temperature represents a modified number of degree-days to estimate the daily snowmelt ( $\mathrm{Li}$ et al. 2014b). Using average daily $>0{ }^{\circ} \mathrm{C}$ cumulative temperature instead of the average daily temperature can precisely assess the snowmelt process in alpine watersheds, which are dominated by snowmelt water (Yu et al. 2013a; Li et al. 2014b). The daily variation of temperature can be represented by a cosine cycle within the maximum and minimum bounds (Campbell 1985). The average daily $>0{ }^{\circ} \mathrm{C}$ cumulative temperature was calculated by summing the $>0{ }^{\circ} \mathrm{C}$ hourly temperature within a day. However, the observed hourly temperature was absent except for the observed daily mean temperature, daily maximum temperature, and daily minimum temperature. In order to obtain the hourly temperature, the daily maximum and minimum temperature was used to simulate the hourly temperature. 


$$
A T P=\left\{\begin{array}{lll}
\frac{\int_{1}^{24} T_{h r} d t}{24}, & \text { if } \quad T_{h r}>0 \\
0, & \text { if } \quad T_{h r} \leq 0
\end{array}\right.
$$

where ATP is the average daily $>0{ }^{\circ} \mathrm{C}$ cumulative temperature, and $T_{h r}$ is the air temperature at the $h r^{\text {th }}$ hour of a day. $T_{h r}$ can be calculated by the following equation, based on the maximum and minimum daily temperatures (Campbell 1985):

$T_{h r}=T+\frac{\left(T_{m x}-T_{m n}\right)}{2} \times \cos (a \times(h r-15))$,

where $T$ is the mean temperature of the day, the maximum daily temperature is assumed to occur at 15:00 h, and the minimum daily temperature occur at 3:00 h (Campbell 1985). $T_{m x}$ is the observed daily maximum temperature $\left({ }^{\circ} \mathrm{C}\right), T_{m n}$ is the observed daily minimum temperature $\left({ }^{\circ} \mathrm{C}\right)$, and ' $a$ ' is a constant with a value of 0.2618 .

In order to reflect the fate of snowmelt water in the snowpack due to the refreezing process, this study assumed that a threshold value of ATP (ATP threshold $\left._{\text {d }}\right)$ exists. As the ATP is less than the $A T P_{\text {threshold }}$, the snowmelt water cannot charge the streamflow due to the refreezing process of snowmelt water; only when the $A T P$ is greater than the $A T P_{\text {threshold, the }}$ snowmelt water charges the streamflow effectively. The effective daily $>0{ }^{\circ} \mathrm{C}$ cumulative temperature $\left(A T P_{\mathrm{e}}\right)$ with the differences between ATP and $A T P_{\text {threshold }}$ was defined to estimate the effective snowmelt rate:

$$
\begin{aligned}
& A T P_{e}=A T P-A T P_{\text {threshold }} \\
& R_{S M}=\beta \times A T P_{e}
\end{aligned}
$$

where $\beta$ is the modified degree-day factor for snowmelt $\left(\mathrm{cm}{ }^{\circ} \mathrm{C}^{-1}\right.$ day $\left.^{-1}\right)$.

\subsubsection{Water infiltration from the surface-soil layer}

At the beginning of the snowmelt period, surface soil may be frozen, which can prevent the melting water from infiltrating into the soil layer (Shanley and Chalmers 1999; $\mathrm{Li}$ and Simonovic 2002). In the original system-dynamics model ( $\mathrm{Li}$ and Simonovic 2002), the air temperature was used to evaluate the infiltration of water into the surface soil layer. In this study, with regard to water infiltration from the surface-soil layer to the subsurface-soil layer as well as percolation from the subsurface-soil layer to the groundwater layer, the soil temperatures at depths of 20 and $40 \mathrm{~cm}$ were used to adjust infiltration and percolation rates of the two intermediate layers. This assumes that the surface and subsurface soil thawed and the meltwater infiltration and percolation occurred when the soil temperature at 20- and $40-\mathrm{cm}$ depths were greater than $0{ }^{\circ} \mathrm{C}$. Based on Li and Simonovic (2002), percolation rates of the surface and subsurface soil were modified as:
$R_{P 1}= \begin{cases}c_{3}\left(S_{m s}-S_{m s s}\right)^{3} C_{t i} & \text { if } S_{m s}-S_{m s s}>0.01 \text { and } T_{20}>0 \\ 0 & \text { if } S_{m s}-S_{m s s} \leq 0.01 \text { or } T_{20} \leq 0\end{cases}$

$R_{P 2}=\left\{\begin{array}{rlr}c_{4} S_{m s s}^{\lambda} & \text { if } & T_{40}>0 \\ 0 & \text { if } & T_{40} \leq 0\end{array}\right.$

where $R_{P 1}$ and $R_{P 2}\left(\mathrm{~cm} \mathrm{day}^{-1}\right)$ were the percolation rates from the surface-soil layer and subsurface-soil layer, respectively; $c_{3}$ and $c_{4}\left(\mathrm{~cm} \mathrm{day}^{-1}\right)$ were coefficients for surface and subsurface soil infiltration and percolation, respectively; $S_{m s}$ and $S_{m s s}$ (dimensionless) were the effective moisture saturation in the surface and subsurface soil layers, respectively; $\lambda$ was the exponential coefficient that expresses the effect of water saturation on percolation; $T_{20}$ and $T_{40}$ were the soil temperature at $20-$ and $40-\mathrm{cm}$ depths, respectively, estimated by artificial neural network, as described in the next section.

\subsubsection{Estimation of soil temperature at 20- and 40-cm depths}

Although temperatures for both the air and the surface soil were measured for more than 50 years in the target basin, deep-soil temperatures started to be measured only in recent years. Due to the lack of observed soil temperatures during most historical years, an artificial neural network (ANN) was used to reconstruct the soil temperature at 20and $40-\mathrm{cm}$ depths, using the air temperature and surfacesoil temperature as input parameters. A feed-forward ANN structure with a back-propagation (BP) algorithm was used in this study to simulate the soil temperature. Two-layered BP feed-forward neural networks (FFNNs) were trained, using the Levenberg-Marquardt algorithm. The hyperbolic tangent sigmoid (TANSIG) transfer function was used in the first layer, with ten neurons; the Purelin transfer function was used in the second layer. The linear regression method was used to compare the simulation capabilities of soil temperature with the ANN method. Results of the training and validation of the network architecture and linear regression were evaluated by statistical indexes, which included Pearson's correlation coefficient (R) at a 0.01 level ( $p$ value), the root-mean-square error (RMSE), and the mean absolute error (MAE).

\subsubsection{Catchment zoning}

In alpine watersheds with a wide range in elevation, geographic conditions and physical environment vary greatly, which diversifies the water sources contributing to streamflow. As a typical alpine watershed, the Kaidu river basin ranges from 1,400 to 4,794 $\mathrm{m}$ in elevation. At high elevation, 
a glacier area with $445 \mathrm{~km}^{2}$ exists (Li et al. 2003), which accounts for $2.36 \%$ of the study area. The precipitation in the high mountains occurs as snowfall the whole year due to low temperatures, which implies that glacier-melt and snowmelt are the main water sources contributing to streamflow at high elevations. At middle and low elevations, precipitation occurs as snowfall in winter and rainfall in summer, while snowfall and rainfall occurs in an alternate fashion in spring and autumn. The main water sources contributing to streamflow is snowmelt water along with some rainfall at middle elevations, and rainfall with snowmelt water at low elevations. According to the different water sources contributing to runoff, the Kaidu river basin was divided into three sub-catchments: upstream at high elevations (GMH) where the runoff is generated by glacier-melt and snowmelt water; middle stream at middle elevations (SMM) where the runoff is mainly contributed by snowmelt water and rainfall; and downstream at lower elevations (RL) where the runoff is generated by rainfall and snowmelt water. The glacier-melt and snowmelt water were calculated by using the modified degree-day factor (Yu et al. 2013a). In order to differentiate the glacier-melt and snowmelt rates, different degree-day factors were used in this study in different sub-catchments due to different density of glacier and snow ( $\mathrm{Li}$ et al. 2014b). The details of the three sub-catchments are shown in Table 1.

\subsubsection{Precipitation and temperature extrapolated from observed data}

There is only one observation station with long time series temperature and precipitation data, located at Bayinbuluk in the basin, which was not enough to calibrate and validate the model with three sub-catchments. In order to estimate the change of precipitation and temperature with elevation, Fontaine et al. (2002) used the lapse rate to extrapolate temperature and precipitation:

$T_{i}=T_{0}+a_{t i 0}\left(\frac{H_{0}-H_{i}}{100}\right)$

$P_{i}=P_{0}-a_{p i 0}\left(\frac{H_{0}-H_{i}}{100}\right)$

where $T_{i}$ is the temperature of catchment $i, T_{0}$ is the observed temperature of the base station, $a_{t i d} / 100$ is the temperature lapse rate per $100 \mathrm{~m}$ between catchment $i$ and the base station, $H_{O}$ is the elevation of the base station, $H_{i}$ is the average elevation of catchment $i, P_{i}$ is the precipitation of catchment $i, P_{O}$ is the precipitation of the base station, and $a_{p i o} / 100$ is the precipitation lapse rate per $100 \mathrm{~m}$ between the base station and catchment $i$.

The lapse rates of temperature, including the mean temperature, the surface temperature, and ATP, and precipitation vary based on the elevation of the extrapolated catchment. The stations located within or near the watershed include Kuerle (932 m), Yanqi (1056 m), Heshuo (1,086 m), Baluntai (1,740 m), Wuqia (2,177.6 m), Bayinbuluk (2,459 $\mathrm{m})$, Tashikuergan $(3,094 \mathrm{~m})$, and Tuergate $(3,504 \mathrm{~m})$, and the lapse rates of temperature and precipitation in this study were estimated on the basis of the observations from those stations.

\subsubsection{Classification of the streamflow}

The $\mathrm{Z}$ index has been considered more suitable than other indices to describe high-flow and low-flow features of the water resources in northwestern China (Zhang et al. 1998, Wang et al. 2009). This index was used in this study to differentiate the high-flow and low-flow years. The equation of the $\mathrm{Z}$ index (Ling et al. 2013) is:

$Z_{i}=\frac{6}{c_{s}}\left(\frac{c_{s}}{2} \phi_{i}+1\right)^{1 / 3}-\frac{6}{c_{s}}+\frac{c_{s}}{6}$

where $\mathrm{Z}_{i}$ is the $\mathrm{Z}$ index of year $i(\mathrm{i}=1,2, \ldots, \mathrm{n}) ; \mathrm{c}_{\mathrm{s}}$ is the coefficient of the skew of the annual runoff; $\Phi_{i}$ is the standard variable, which can be expressed first by subtracting the annual runoff of year $i$ and the average annual runoff during study period and then dividing by the standard variation of the annual runoff during the study period.

Based on the $\mathrm{Z}$ index and the threshold value of $\mathrm{Z}$ index for different kinds of flows as described by Ling et al. (2013), the streamflow from 1982 to 2002 in Dashankou hydrological station was divided into three categories: normal flow, high flow, and low flow. The years of these three categories of flow were divided into calibration years and validation years, with first $50 \%$ years used for calibration and remaining half for validation. The calibration and validation years of these three kinds of flows were shown in Table 2.
Table 1 Three sub-catchments in the Kaidu River Basin

\begin{tabular}{llll}
\hline Sub-catchments & Elevation range $(\mathrm{m})$ & Average elevation $(\mathrm{m})$ & Area $\left(\mathrm{km}^{2}\right)$ \\
\hline GMH & $>3,950$ & 4069.89 & 641.97 \\
SMM & $2,675-3,950$ & 3171.09 & 12345.4 \\
RL & $1,400-2,675$ & 2463.91 & 5737.66 \\
\hline
\end{tabular}




\subsection{Model evaluation methods}

The performance of the model was evaluated using sensitivity analysis, scatter plots, and box plots as well as three statistical measures, i.e., the Nash Sutcliff coefficient (NSE), root-mean-square error-observations standard deviation (RSR), and percentage bias (PBIAS). This study ensured the capability of the model as applied to the inland river basins of the Tianshan Mountains. The sensitivity analysis was used to calibrate the robustness of the model. Scatter plots and box plots visually showed the capability of the modified model with regard to these three categories of flows, while the statistical measures quantitatively evaluated the capability of the modified model with regard to these three kinds of flows.

\subsubsection{Sensitivity analysis}

Following Li and Simonovic (2002), the sensitivity analysis was applied by varying the parameters by approximately \pm $10 \%$ of the baseline value; the responses of the streamflow to this variation were analyzed as well. The following equations were used to calculate the sensitivity of the model's parameters:

$\bar{s}=\frac{\sum_{t=1}^{n} \frac{Q_{S t}^{\prime}-Q_{S t}}{Q_{S t}}}{n} \times 100 \%$

$s_{p}=\frac{Q_{S p}^{\prime}-Q_{S p}}{Q_{S p}} \times 100 \%$

where $\bar{s}$ and $s_{p}$ represent the averaged sensitivity of the streamflow and the peak value, respectively, to parameter variations; $n$ is the length of the time horizon; $t$ is the time step; $Q_{S t}$ is the simulated streamflow that corresponds to the calibrated parameter value at time $t ; Q_{S t}^{\prime}$ is the streamflow corresponding to the modified parameter value; and $Q_{s p}$ and $Q_{S p}^{\prime}$ stand for the peak flows that correspond to the calibrated parameter value at time $t$ and to the modified parameter value, respectively.

\subsubsection{Statistical analysis}

The statistical measures used included the Nash Sutcliff coefficient (NSE), root-mean-square error-observations standard deviation (RSR), and percentage bias (PBIAS). NSE indicates the predictive power of the hydrological models (Moriasi et al. 2007) and determines the relative magnitude of the residual variance ('noise') compared to the measured data variance (Nash and Sutcliffe 1970). It is calculated as follows:

$N S E=1-\frac{\sum_{t=1}^{n}\left(Q_{M t}-Q_{S t}\right)^{2}}{\sum_{t=1}^{n}\left(Q_{M t}-\bar{Q}_{M}\right)^{2}}$

where $Q_{M t}$ and $Q_{S t}$ are the observed and simulated streamflow values, respectively, at time $t$; and $\bar{Q}_{M}$ is the measured mean value. NSE ranges from $-\infty$ to 1 , where 1 corresponds to a perfect match between observed and simulated values.

RSR is the ratio of the daily root-mean square (DRMS) to the standard deviation of the observed value (SD). The smaller the DRMS value, the better the model performance (Gupta et al. 1999). RSR can be calculated as:

$R S R=\frac{D R M S}{S D}=\frac{\sqrt{\sum_{t=1}^{n}\left(Q_{M t}-Q_{S t}\right)^{2}}}{\sqrt{\sum_{t=1}^{n}\left(Q_{M t}-\bar{Q}_{M}\right)^{2}}}$

RSR ranges from 0 to $+\infty$, where 0 is the optimal value. This indicates a DRMS of 0 or a residual variation; therefore, it is a perfect model simulation. The lower the RSR, the lower the DRMS, and the better the performance of the model simulation (Moriasi et al. 2007).

PBIAS is the deviation of data being evaluated, which measures whether the model output is smaller or larger than the corresponding observed values (Gupta et al. 1999). It is expressed as a percentage. PBIAS is calculated as follows:

$P B I A S=\frac{\sum_{t=1}^{n}\left(Q_{M t}-Q_{S t}\right) \times 100}{\sum_{t=1}^{n} Q_{M t}}$

The optimal value of PBIAS is 0.0, with a low-magnitude value indicating an accurate model simulation. A positive value of PBIAS indicates that the model is underestimating, and a negative value indicates that the model is overestimating (Gupta et al. 1999).

Table 2 Classification of flows from 1982 to 2002 in the Kaidu River Basin

\begin{tabular}{lllll}
\hline Types of flow & $\mathrm{Z}$ index & Cumulative frequency $(\%)$ & Calibration years & Validation years \\
\hline Normal & $-0.5244<Z \leq 0.5244$ & $30-70$ & $1982,1987,1988,1989$ & $1991,1992,1993,1997$ \\
High & $\mathrm{Z}>0.5244$ & $>70$ & $1994,1996,1998,1999$ & $2000,2001,2002$ \\
Low & $\mathrm{Z} \leq-0.5244$ & $<30$ & $1983,1984,1985$ & $1986,1990,1995$ \\
\hline
\end{tabular}




\subsection{Model implementation}

A modified hydrological model was implemented using the iThink 9.0.2 software. The ANN model was built using the MATLAB software. The statistical analysis was implemented in Microsoft Excel.

The iThink platform can import and export the .xls format file, which provides an opportunity for the integration of the ANN model as well as statistical analysis with the SD model. The results simulated by the ANN model were saved as .xls format file which was imported into the iThink platform to simulate the infiltration rate in various soil layers. The results simulated by the hydrological model in SD were exported in an .xls format file which was used to evaluate the performance of the model through statistical analysis in Excel.

\section{Results and discussion}

\subsection{Soil temperature at 20- and 40-cm depths}

The soil temperatures at Bayinbuluk station in 2005 and 2006 were used to train and validate the ANN model, respectively. The evaluation results of the training and validation periods for ANN model are shown in Table 3. The ANN model used a $(2,10,1)$ structure. The correlation coefficients of the training and validation periods in 20and $40-\mathrm{cm}$ soil temperatures were more than 0.95 . The root-mean-square errors ranged from 4.21 and 7.70, and the mean absolute errors were less than 3 .

The linear regression formulas for soil temperature at 20- and 40-cm depths were:

$T_{20}=0.192 T+0.438 T_{0}+2.146$

$T_{40}=0.175 T+0.341 T_{0}+2.924$

where $T_{0}$ represents the surface soil temperature and $T$ stands for the daily mean temperature. For the linear regression model, the correlation coefficients of the training and validation periods at depths of $20-$ and $40-\mathrm{cm}$ soil temperatures were more than 0.93 . However, the rootmean-square errors ranged from 10 to 20 , and the mean absolute errors were more than 3 . A comparison with the linear regression model indicated the ANN model can simulate the soil temperature satisfactorily. Hence, the trained ANN model was used to reconstruct the soil temperature at 20- and 40-cm depths for hydrological modeling using observed air temperature and surface-soil temperature as inputs for study period.

\subsection{Simulation runs of the modified model for three} kinds of flows

Since the annual runoff varies annually, the simulation capability of the modified model on different kinds of flows needed to be evaluated. The modified model was calibrated and validated using the streamflow from calibration and validation years corresponding to normal flow, high flow and low flow. Figure 3 provides the observed and simulated streamflows of the normal flow, high flow and low flow at Dashankou Station for the calibration and validation years as well as their relationship with the observed $A T P_{e}$ and precipitation at Bayinbuluk Station.

The simulated spring-peak flow matched the observed spring-peak flow very well for all the calibration and validation years of these three categories of flows. On the other hand, the simulated summer-peak flow, contributed by heavy rainfall, did not match the observed summer-peak flow as well as the simulated spring-peak flow did. During the spring, the changing curve of the streamflow was consistent with that of the $A T P_{e}$, indicating that a close relation existed between the spring streamflow and $A T P_{e}$. The main reason was that snowmelt mainly contributes to the river runoff in the spring. Snowmelt water is controlled by both the volume of the snowpack in the previous winter and daily $>0{ }^{\circ} \mathrm{C}$ cumulative temperature in the spring (Zhang et al. 2014).

Table 3 Evaluation results of the calibration and validation periods

\begin{tabular}{|c|c|c|c|c|c|}
\hline \multirow[t]{2}{*}{ Method } & \multirow[t]{2}{*}{ Statistical index } & \multicolumn{2}{|c|}{ Soil temperature at a $20-\mathrm{cm}$ depth } & \multicolumn{2}{|c|}{ Soil temperature at a $40-\mathrm{cm}$ depth } \\
\hline & & Calibration & Validation & Calibration & Validation \\
\hline \multirow[t]{3}{*}{ ANN } & $\mathrm{R}$ & 0.98 & 0.98 & 0.95 & 0.96 \\
\hline & RMSE & 4.89 & 4.21 & 7.70 & 6.04 \\
\hline & MAE & 1.66 & 1.62 & 2.08 & 1.94 \\
\hline \multirow[t]{3}{*}{ Linear regression } & $\mathrm{R}$ & 0.96 & 0.97 & 0.93 & 0.94 \\
\hline & RMSE & 10 & 12 & 15 & 20 \\
\hline & MAE & 3.02 & 3.54 & 3.65 & 4.5 \\
\hline
\end{tabular}


Fig. 3 Results of the observed streamflow (solid black line) and simulated streamflow (dotted line) at Dashankou Station compared to the effective $>0{ }^{\circ} \mathrm{C}$ cumulative temperature (red line) and precipitation (blue line) at Bayinbuluk Station for normal flow, high flow and low flow during the calibration and validation years; a calibration results of normal flow,

b validation results of normal flow, c calibration results of high flow, $\mathbf{d}$ validation results of high flow, e calibration results of low flow, and $\mathbf{f}$ validation results of low flow (a)

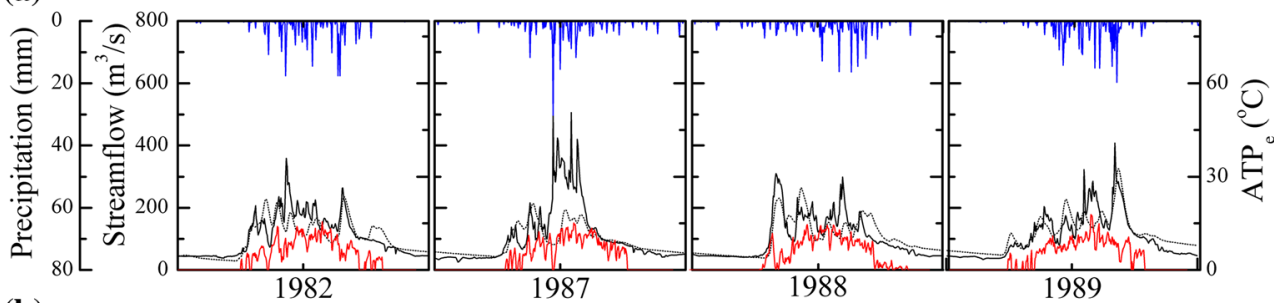

(b)
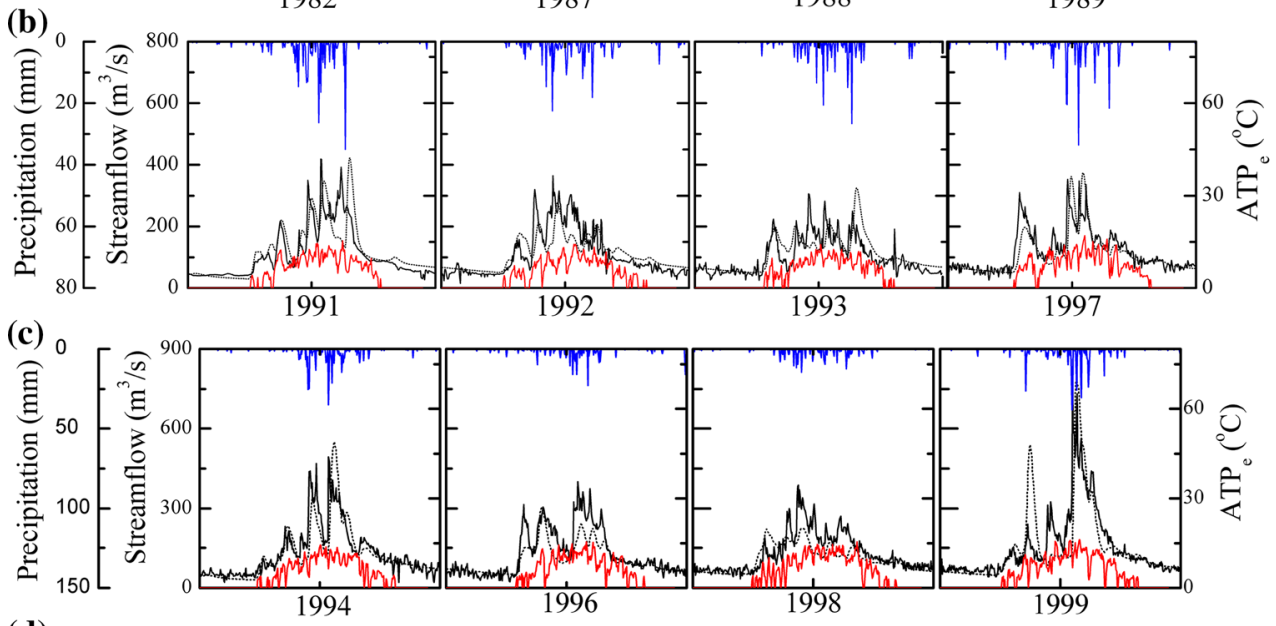

(d)

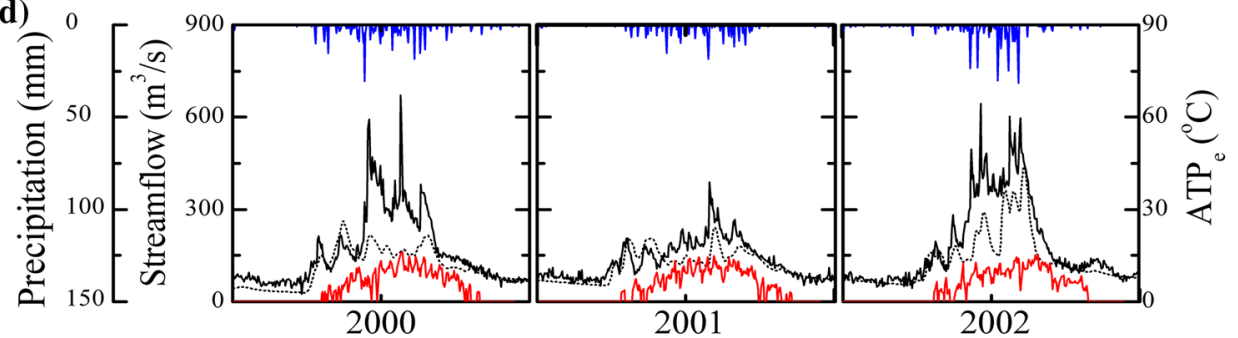

(e)

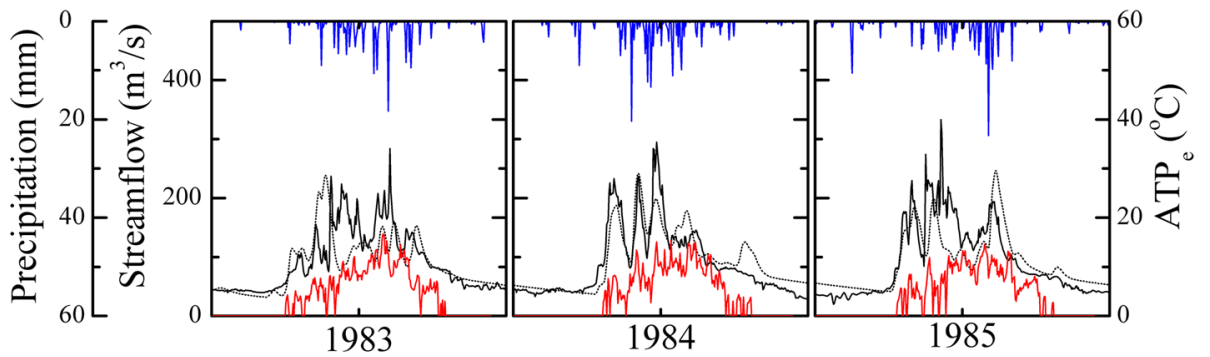

(f)

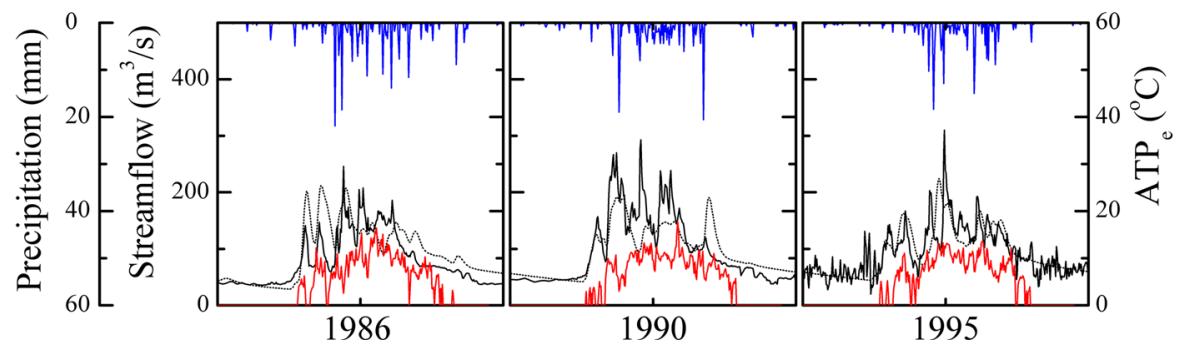

The volume of the snowpack in the spring depends on snowfall from the previous winter, but snowmelt intensity in spring is determined by the daily $>0{ }^{\circ} \mathrm{C}$ cumulative temperature during the snowmelt season. A significant amount of $A T P_{e}$ melted a great deal of snow, which could have caused the spring-peak flow. By summer, the temperature was $>0{ }^{\circ} \mathrm{C}$, most of the snowpack had melted, and precipitation fell as rain rather than snow. Hence, rainfall in the basin became the main contributor to the streamflow. Heavy rainfall could be the cause of the summer-peak flow. 
In some peaks, the changing curve of the precipitation in Fig. 3 from Bayinbuluk meteorological station did not match the summer-peak flow very well. This may have resulted from the spatial heterogeneity of precipitation distribution due to the complexity of topography, vegetation, and the variation in elevations. This study applied linear extrapolation, a commonly accepted method to extrapolate precipitation; however, this may not have fully reflected the heterogeneity of the precipitation distribution.

In all the calibration and validation years, the model could simulate the streamflow very well in winter in all three categories of flows. In winter, the temperature was $<0{ }^{\circ} \mathrm{C}$ and precipitation occurred as snowfall, which could not immediately recharge the streamflow. Good reproduction of streamflow in winter showed that the modified model could simulate the baseflow in winter efficiently because the main water source contributing to the streamflow in winter was the baseflow controlled by soil moisture and groundwater.

\subsection{Performance and capabilities of the modified model}

\subsubsection{Sensitivity analysis}

For the sensitivity analysis during the calibration years, the following factors were selected: (1) a modified degree-day factor for snowmelt $(\beta)$; (2) the maximum of the active temperature when the vegetation cover reached the maximum value $\left(T_{C \max }\right)$; (3) the maximum of the active temperature when the surface soil thawed absolutely $\left(T_{\text {Imax }}\right)$; (4) the growth-exponential coefficient of the vegetation cover $\left(c_{c}\right)$, which is influenced by the active temperature; (5) the exponential coefficient that describes the influence of $T_{I}$ on thawed soil $\left(c_{i}\right)$; and (6) the maximum capacity of canopy interception $\left(C_{\text {max }}\right)$. It was assumed that degree-day factor for snowmelt varied with different sub-catchments. The other five parameters remained the same for all three sub-catchments.

Based on the modified model, the sensitivity of these six parameters for the three categories of flow in calibration years is shown in Table 4. The averaged sensitivity of streamflow and peak value was not sensitive to the selected parameter variations. The most influential factor on $s_{p}$ was $T_{\text {Imax }}$, whose variation by about $\pm 10 \%$ of baseline value led to a variation of $s_{p}$ ranging from -0.21 to $7.09 \%$. The value for $T_{\text {Imax }}$ reflected the thaw process and soil physical state, which partitions the available surface water into soil water and runoff. The frozen soil layer prevented the available surface water from infiltrating into the soil layer. Compared with other selected parameters, the variation in the value of $\beta$ in the sub-catchment SMM had a greater influence on $s_{p}$ because it was the main contributor to snowmelt. The results showed that snowmelt and the frozen state of the surface soil were the important factors for the generation of the peak flow.

Since the average sensitivity indices may have masked the effect on the hydrologic signatures, runoff graphs for the various parameter values are presented in Fig. 4. The calibration years of these three kinds of flows were not sequential, and the runoff in 1982, 1994, and 1993 were selected to show the sensitivity of the normal flow, high flow and low flow, respectively. The results indicate that streamflow was not sensitive to these selected parameters. However, these parameters had a greater influence on the spring streamflow than on the summer streamflow and winter streamflow. Furthermore, the variation of the runoff under parameter $\beta$ in sub-catchment SMM and $\mathrm{T}_{\text {Imax }}$ in spring was greater. The results from the runoff graphs are consistent with those from the averaged sensitivities of the streamflows and peak values.

\subsubsection{Comparison of flows using scatter plots and box plots}

The scatter plots and box plots in Fig. 5 show the observed and simulated normal flows, high flows, and low flows during the calibration and validation years. In the scatter plots, the solid line in the middle represents the $45^{\circ}$ bisector line at the 1:1 slope, and $\mathrm{R}$ represents the correlation coefficient between the observed and simulated streamflow. The plots reveal whether the model overestimated or underestimated the streamflow (Dawadi and Ahmad 2012). Data points close to the $45^{\circ}$ bisector line indicate a perfect fit between the observed and simulated streamflow. In the box plots, the box represents 25 th and 75 th percentile values of the streamflow. The solid horizontal line within the box represents the median value of the streamflow. The whiskers in the lower end and upper end of the box plot represent the 5th and 95th percentile values of the streamflow.

In Fig. 5a, the scatter plots show that the simulated streamflow in the normal flow case was underestimated in the calibration years and overestimated in the validation years. For the calibration and validation years, the simulation of streamflow with low values of about $<100 \mathrm{~m}^{3} \mathrm{~s}^{-1}$ was better than that for streamflow with high values. The correlation coefficients of the observed and simulated streamflows in the calibration and validation years were 0.75 and 0.78 , respectively, which is acceptable.

In the box plots of Fig. 5a, the 95th value of the simulated streamflow was lower than that of the observed streamflow in calibration years and validation years. However, values for the median, 25th percentile, and 75th percentile of the simulated streamflow were similar to that of the observed streamflow. This indicates that the median, 
Table 4 Sensitivity analysis of the model (\%)

\begin{tabular}{|c|c|c|c|c|c|c|c|c|c|c|c|c|c|c|c|c|}
\hline \multirow{2}{*}{$\begin{array}{l}\text { Parameter } \\
\text { change }(\%)\end{array}$} & \multicolumn{2}{|c|}{$\beta(\mathrm{GMH})$} & \multicolumn{2}{|c|}{$\beta(\mathrm{SMM})$} & \multicolumn{2}{|l|}{$\beta(\mathrm{RL})$} & \multicolumn{2}{|l|}{$T_{\text {Imax }}$} & \multicolumn{2}{|l|}{$T_{C \max }$} & \multicolumn{2}{|l|}{$c_{c}$} & \multicolumn{2}{|l|}{$c_{i}$} & \multicolumn{2}{|l|}{$C_{m a}$} \\
\hline & -10 & +10 & -10 & +10 & -10 & +10 & -10 & +10 & -10 & +10 & -10 & +10 & -10 & +10 & -10 & +10 \\
\hline \multicolumn{17}{|l|}{ Normal flow } \\
\hline $\bar{s}$ & -0.11 & 0.10 & -1.02 & 0.93 & -0.21 & 0.19 & 0.04 & -0.05 & -1.00 & 1.00 & -0.38 & 0.33 & 0.07 & -0.06 & 0.75 & -0.72 \\
\hline$s_{p}$ & -0.02 & 0.02 & 0.04 & -0.07 & 0.00 & 0.00 & 0.20 & -0.21 & -1.31 & 1.03 & -0.32 & 0.29 & 0.18 & -0.15 & 0.91 & -0.89 \\
\hline \multicolumn{17}{|l|}{ High flow } \\
\hline $\bar{s}$ & -0.10 & 0.09 & -0.87 & 0.80 & -0.16 & 0.15 & 0.00 & 0.00 & -0.79 & 0.77 & -0.31 & 0.27 & 0.05 & -0.04 & 0.68 & -0.66 \\
\hline$s_{p}$ & -0.01 & 0.01 & 0.00 & 0.00 & 0.01 & 0.00 & 0.11 & -0.09 & -0.47 & 0.47 & -0.19 & 0.17 & 0.07 & -0.06 & 0.30 & -0.29 \\
\hline \multicolumn{17}{|l|}{ Low flow } \\
\hline $\bar{s}$ & -0.08 & 0.08 & -0.71 & 0.65 & -0.16 & 0.14 & 0.08 & -0.08 & -0.68 & 0.70 & -0.29 & 0.25 & 0.07 & -0.06 & 0.50 & -0.47 \\
\hline$s_{p}$ & -0.02 & 0.02 & 0.04 & 3.50 & 0.01 & -0.01 & 0.39 & 7.09 & -1.02 & 1.02 & -0.48 & 0.42 & 0.37 & 2.99 & 0.73 & -0.72 \\
\hline
\end{tabular}

25 th percentile and 75th percentile values could be matched very well. The results of the scatter plots and box plots in Fig. 5a indicate that the modified model could simulate normal flow quite well.

In Fig. 5b, the scatter plots show that in the case of high flow, the simulated streamflow was overestimated in the calibration years and underestimated in the validation years. The simulation of the streamflow with low values of about $<150 \mathrm{~m}^{3} \mathrm{~s}^{-1}$ was better than that for streamflows with high values for the calibration and validation years. The correlation coefficients of the observed and simulated streamflow in the calibration and validation years were 0.80 and 0.83 , respectively, which is acceptable.

In the box plot of Fig. 5b, the 95th and the 75th percentile values of the simulated streamflow were lower than that for the observed streamflow in the calibration years, while the median value and the 25 th percentile value of the simulated streamflow were similar to that of the observed streamflow. The 95th percentile value of the simulated streamflow was lower than that of the observed streamflow in validation years, while values for the median, the 25 th percentile, and the 75th percentile of the simulated streamflow were similar to that of the observed streamflow. This indicates that the median value and the 25 th percentile values can be matched very well. Results for the scatter plots and box plots indicate that the modified model can simulate high flow well.

For low flow, as shown in Fig. 5c, the scatter plots showed that the simulated streamflow was overestimated in the validation years. The simulation of streamflow with low values of about $<100 \mathrm{~m}^{3} \mathrm{~s}^{-1}$ was better than streamflow with high values for both the calibration and validation years. The correlation coefficients of the simulated streamflow and observed streamflow in the calibration and validation years were 0.78 and 0.77 , respectively, which is acceptable. The values for the median, the 25 th percentile, and the 75th percentile as well as values for the 5th and 95th percentiles of the simulated streamflow were similar to that of the observed streamflow in the calibration and validation years. This shows that they could be simulated fairly well. All the results for the scatter plots and box plots in the calibration and validation years indicated that the modified model could simulate low flow very well.

\subsubsection{Statistical performance}

Moriasi et al. (2007) recommended general performance ratings for the statistical measures of the monthly time step. Since the daily time step was used in this study, the statistical measures were calculated based on daily and monthly time steps. The results are provided in Table 5 for the calibration and validation years of the three types of flows.

In the daily time step, the values of NSE were $>0.5$, the values of RSR were less than or equal to 0.7 , and the values of PBIAS were $< \pm 25$ for all three kinds of flows during both the calibration and validation years. This indicates that the modified model performed satisfactorily in a daily time step based on criteria provided by Moriasi et al. (2007).

The results in Table 5 show that the modified model performed better with the monthly time step than with the daily time step. In cases of normal flow in calibration years, the NSE, RSR, and PBIAS had values of 0.67, 0.57 and 2.61 , respectively, which were good, good, and very good, respectively. These three statistical measures performed very well in validation years, with $0.82,0.43$, and -2.64 , respectively. In cases of high flow in calibration years, the NSE, RSR, and PBIAS had values of 0.77, 0.48, and 9.93, respectively, all of which were very good. During the validation years, NSE, RSR and PBIAS had values of 0.56 , 0.66 and 24.31, respectively, and therefore performed satisfactorily. In cases of low flow in calibration years, NSE and RSR had values of 0.73 and 0.52 , respectively, and thus performed well; in the validation years, the values were 0.76 and 0.49 , respectively, and so they performed 
Fig. 4 Result of the sensitivity analyses for a normal flow (1982), b high flow (1994), and c low flow (1993)

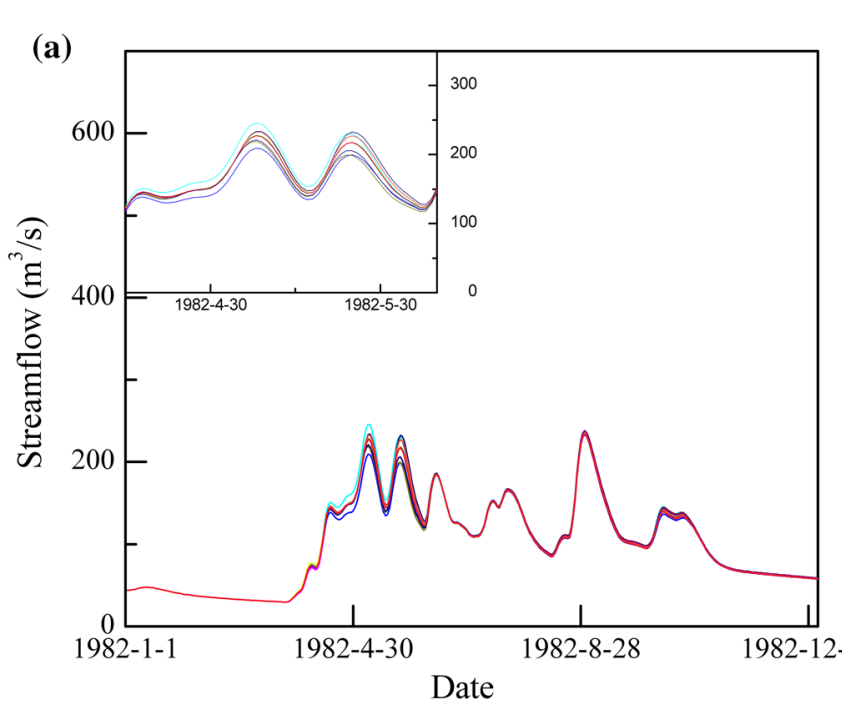

- Simulated Streamflow
$\beta(\mathrm{GMH})-10 \%$
$\beta(\mathrm{GMH})+10 \%$
$\beta(\mathrm{SMM})-10 \%$
$\beta(\mathrm{SMM})+10 \%$
$\beta(\mathrm{RL})-10 \%$
$\beta(\mathrm{RL})+10 \%$
$\mathrm{~T}_{\mathrm{Imax}}-10 \%$
$-\mathrm{T}_{\text {Imax }}+10 \%$
$-\mathrm{T}_{\mathrm{Cmax}}-10 \%$
$-\mathrm{T}_{\mathrm{Cmax}}+10 \%$
$\mathrm{c}_{\mathrm{c}}-10 \%$
$-\mathrm{c}_{\mathrm{c}}+10 \%$
$\mathrm{c}_{\mathrm{i}}-10 \%$
$\mathrm{c}_{\mathrm{i}}+10 \%$
$\mathrm{C}_{\max }-10 \%$
$\mathrm{C}_{\max }+10 \%$

\section{(b)}
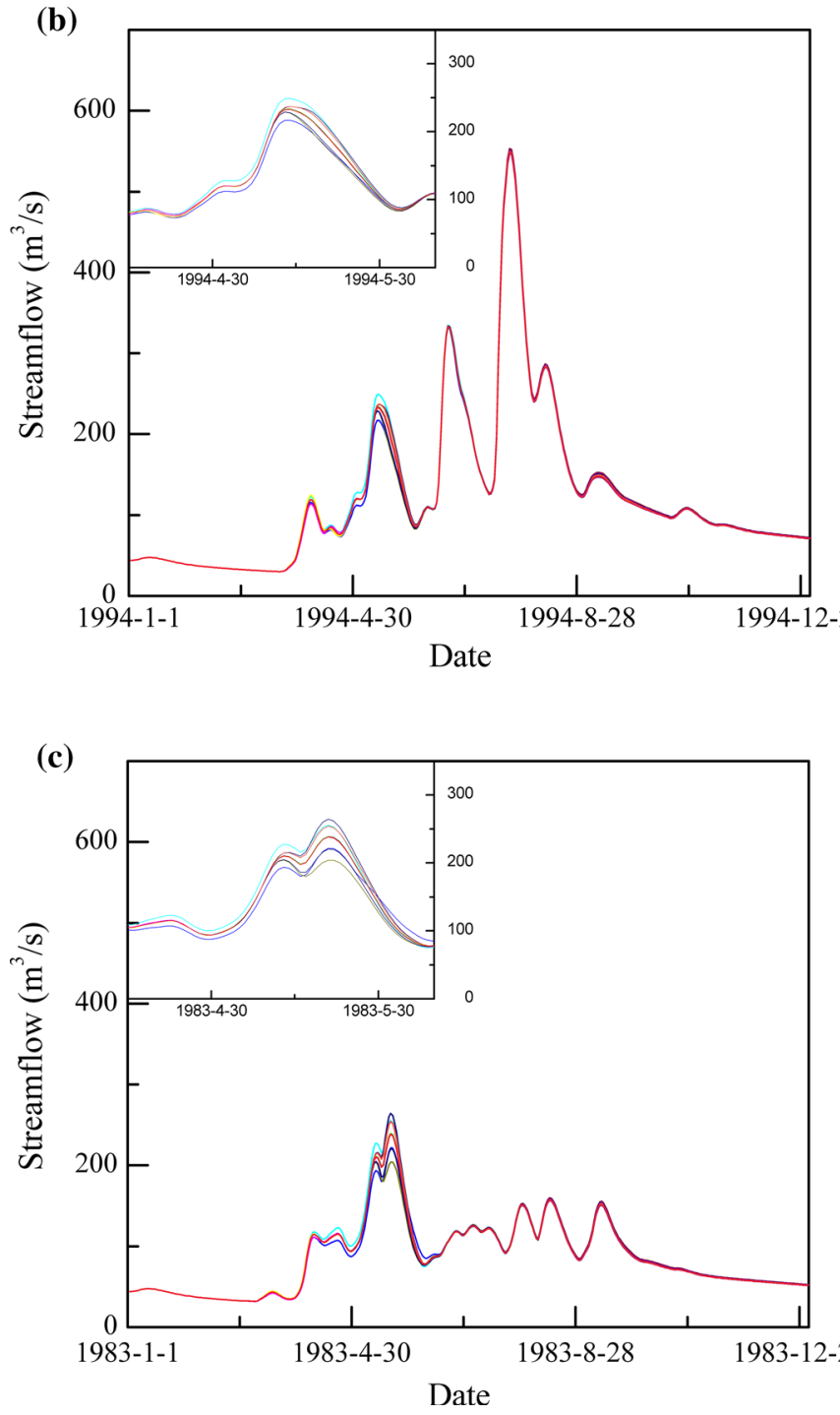

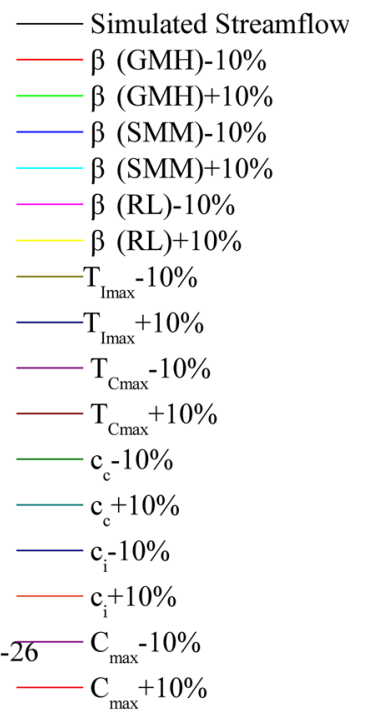

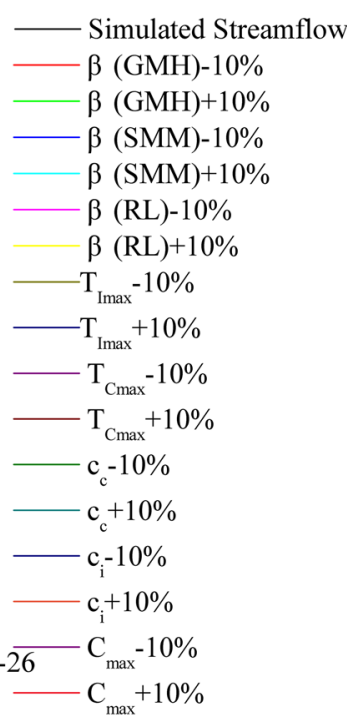


(a)

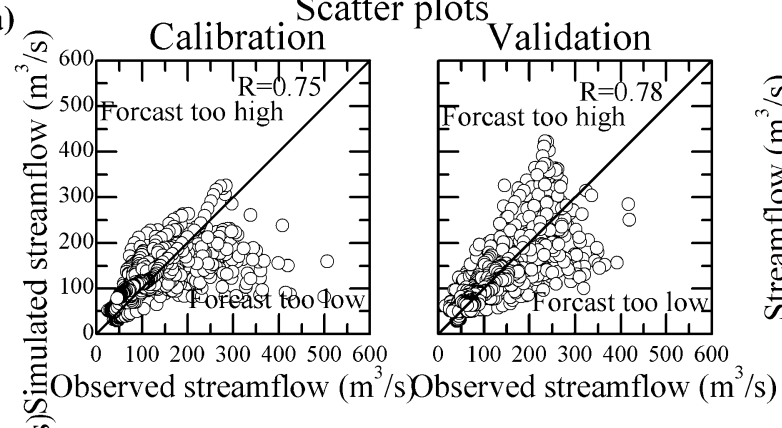

(b)

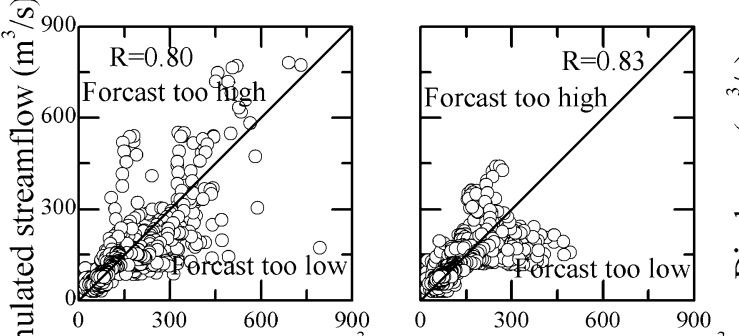

(c)

节Observed streamflow $\left(\mathrm{m}^{3} / \mathrm{s}\right)$ Observed streamflow $\left(\mathrm{m}^{3} / \mathrm{s}\right)$
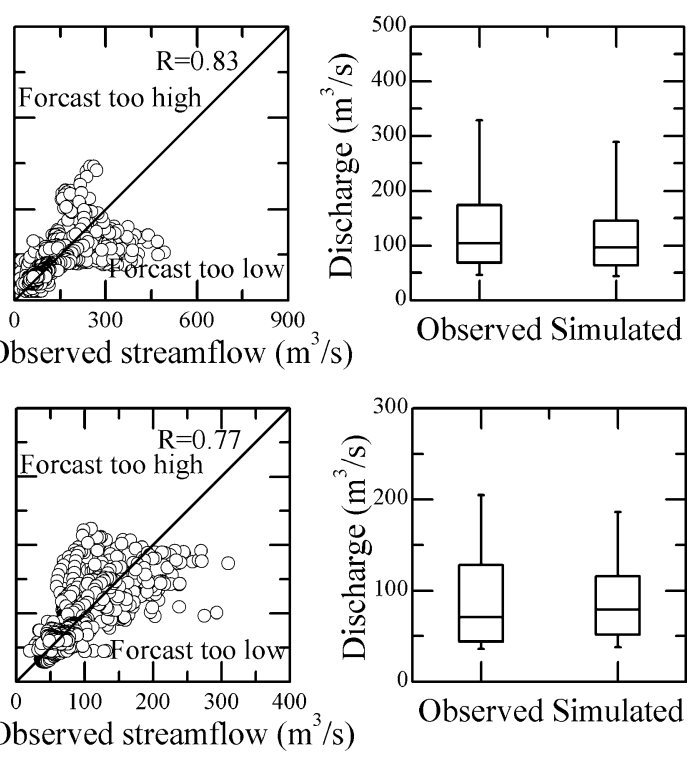

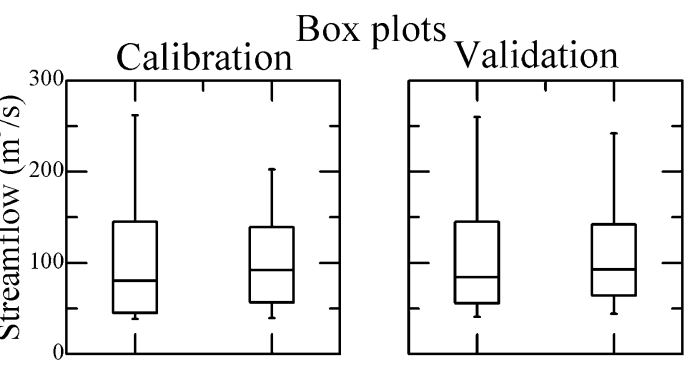

Observed Simulated

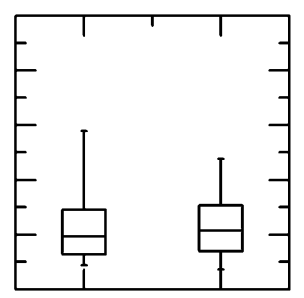

Observed Simulated

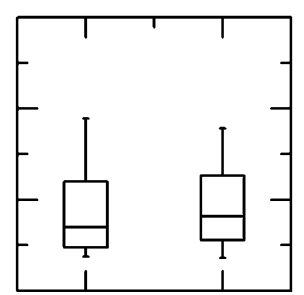

Observed Simulated

Fig. 5 The scatter plots and box plots of the observed and simulated streamflow in the calibration and validation period for a normal flow, $\mathbf{b}$ high flow, and c low flow

very well. In calibration and validation years, PBIAS had values of 0.39 and -4.29 , respectively, and thus performed very well.

Compared to the results for statistical measures in monthly and daily time steps, only the PBIAS values stayed the same during calibration and validation years for the three types of flow. In general, the statistical measures in the daily and monthly time steps indicated that the performances of the modified model for the three kinds of flows were satisfactory. However, from the values of the statistical performance measures for the evaluation of the hydrologic model for both calibration and validation years with a monthly time step, normal flow and low flow performed better than high flow.

\subsection{Behavioral comparison of the modified model with the original model}

In order to demonstrate improvements of the current model, three kinds of modifications focusing on snowmelt rate and water infiltration rate were built:
(1) Modification with both snowmelt rate and water infiltration rate (current modified model): using $A T P_{e}$ instead of $T$ to simulate the snowmelt rate and taking into consideration the influence of the frozen-thaw status under surface soil layer on water infiltration and percolation.

(2) Modification with snowmelt rate and without water infiltration rate (modified on $A T P_{e}$ ): using $A T P_{e}$ instead of $T$ to simulate the snowmelt rate without consideration on the influence of the frozen-thaw status under surface soil layer on water infiltration and percolation.

(3) Modification without snowmelt rate and with water infiltration rate (modified on $T_{\text {soil }}$ ): using the daily mean temperature to calculate the snowmelt rate and taking into consideration the influence of the frozenthaw status under the surface-soil layer on water infiltration and percolation.

The observed and simulated streamflow from 1982 to 2002 under the various modifications are shown in Fig. 6. The streamflow under different kinds of modifications were 
Table 5 Statistical performance measures for the hydrologic model (calibration and verification years, daily and monthly time step)

\begin{tabular}{|c|c|c|c|c|c|c|c|c|c|c|c|c|}
\hline \multirow{3}{*}{$\begin{array}{l}\text { Type } \\
\text { of flow }\end{array}$} & \multicolumn{6}{|c|}{ Calibration } & \multicolumn{6}{|c|}{ Validation } \\
\hline & \multicolumn{2}{|l|}{ NSE } & \multicolumn{2}{|l|}{ RSR } & \multicolumn{2}{|c|}{ PBIAS } & \multicolumn{2}{|l|}{ NSE } & \multicolumn{2}{|l|}{ RSR } & \multicolumn{2}{|l|}{ PBIAS } \\
\hline & Value & Evaluation & Value & Evaluation & Value & Evaluation & Value & Evaluation & Value & Evaluation & Value & Evaluation \\
\hline \multicolumn{13}{|l|}{ Daily } \\
\hline Normal & 0.56 & & 0.67 & & 2.61 & & 0.59 & & 0.64 & & -2.64 & \\
\hline High & 0.58 & & 0.65 & & 9.93 & & 0.52 & & 0.70 & & 24.31 & \\
\hline Low & 0.60 & & 0.63 & & 0.39 & & 0.57 & & 0.66 & & -4.29 & \\
\hline \multicolumn{13}{|l|}{ Monthly } \\
\hline Normal & 0.67 & Good & 0.57 & Good & 2.61 & Very good & 0.82 & Very good & 0.43 & Very good & -2.64 & Very good \\
\hline High & 0.77 & Very good & 0.48 & Very good & 9.93 & Very good & 0.56 & Satisfactory & 0.66 & Satisfactory & 24.31 & Satisfactory \\
\hline Low & 0.73 & Good & 0.52 & Good & 0.39 & Very good & 0.76 & Very good & 0.49 & Very good & -4.29 & Very good \\
\hline
\end{tabular}

simulated as well as the original model. Figure 6a indicates that the current modified model could simulate the timing and the magnitude of the spring streamflow better than the original model. Compared with the simulated streamflow from original model, the simulated spring streamflow from the current modified model could capture the occurrence time and magnitude of spring-peak flow better than the original model. From Fig. 6b, using $A T P_{e}$ instead of $T$ could simulate the spring streamflow better than the original one. The main reason is that $A T P_{e}$ took into consideration the effective $>0{ }^{\circ} \mathrm{C}$ temperature within a day when estimating the snowmelt rate whether the average temperature is $>0{ }^{\circ} \mathrm{C}$ or $<0{ }^{\circ} \mathrm{C}$; this improved the capability of the snowmelt simulation.

The difference between $A T P_{e}$ and $T$ is controlled by the daily minimum temperature. $A T P_{e}$ is greater than $T$ when the daily minimum temperature is $\angle 0{ }^{\circ} \mathrm{C}$, otherwise, $A T P_{e}$ equals to $T$ when the daily minimum temperature is $\geq 0{ }^{\circ} \mathrm{C}$. Hence, the snowmelt rate estimated using $A T P_{e}$ is greater than or equal to the rate that was estimated using $T$ when the daily minimum temperature is $<0{ }^{\circ} \mathrm{C}$. The effective $>0{ }^{\circ} \mathrm{C}$ temperature within a day not only took into consideration the influence of the $>0{ }^{\circ} \mathrm{C}$ cumulative temperature on the snowmelt process, but also accounted for the refreezing process of the snowmelt water, which could not charge the spring streamflow.

From Fig. 6c, the magnitude of the simulated streamflow after the spring-peak flow was greater than in the original model when taking into consideration the water infiltration under the surface-soil layer. The frozen-soil layer had a great influence on the magnitude of the peak flow because it prevented water infiltration. After the spring-peak flow, the meltwater from the frozen soil could recharge the streamflow. However, the improvement in the model when taking into consideration the water infiltration under the surface-soil layer was not as significant as using $A T P_{e}$ instead of $T$ to simulate the spring streamflow.
Based on the results in Fig. 6, the improvement of the two modifications in the model focused on the spring streamflow. Statistical measures were used to evaluate the capability of the two modified parts of the model in simulating the annual streamflow from January to December and the spring streamflow from March to May. From the results of the statistical analysis (Table 6), the correlation coefficients between the simulated streamflow and the observed streamflow were the same for the streamflow from January to December. For the streamflow from March to May, they were greater in the current modified model and the modification on $A_{T P}$ than that under the modification on $T_{\text {soil }}$ and the original model.

With the current modified model and the modification on $A T P_{e}$, NSE was greater than with the modification on $T_{\text {soil }}$ and original model. With the current modified model and the modification on $A T P_{e}$, the statistical measures RSR, PBIAS, RMSE, and MAE were smaller than with the modification on $T_{\text {soil }}$ and original model for the streamflow from January to December as well as the streamflow from March to May. The exception was RSR for the streamflow from January to December, which was the same under the three kinds of modifications and the original model. The variations of the six statistical measures under the three kinds of modifications and the original model for the streamflow from January to December were not as significant as the streamflow from March to May.

\section{Conclusions}

Temperature and precipitation are two key meteorological factors influencing the formation and annual distribution of runoff in inland river basins, where the streamflow is contributed by both precipitation and snowmelt water. In alpine basins where snowmelt water is a main contributor to runoff, the temperature is believed to be an important 

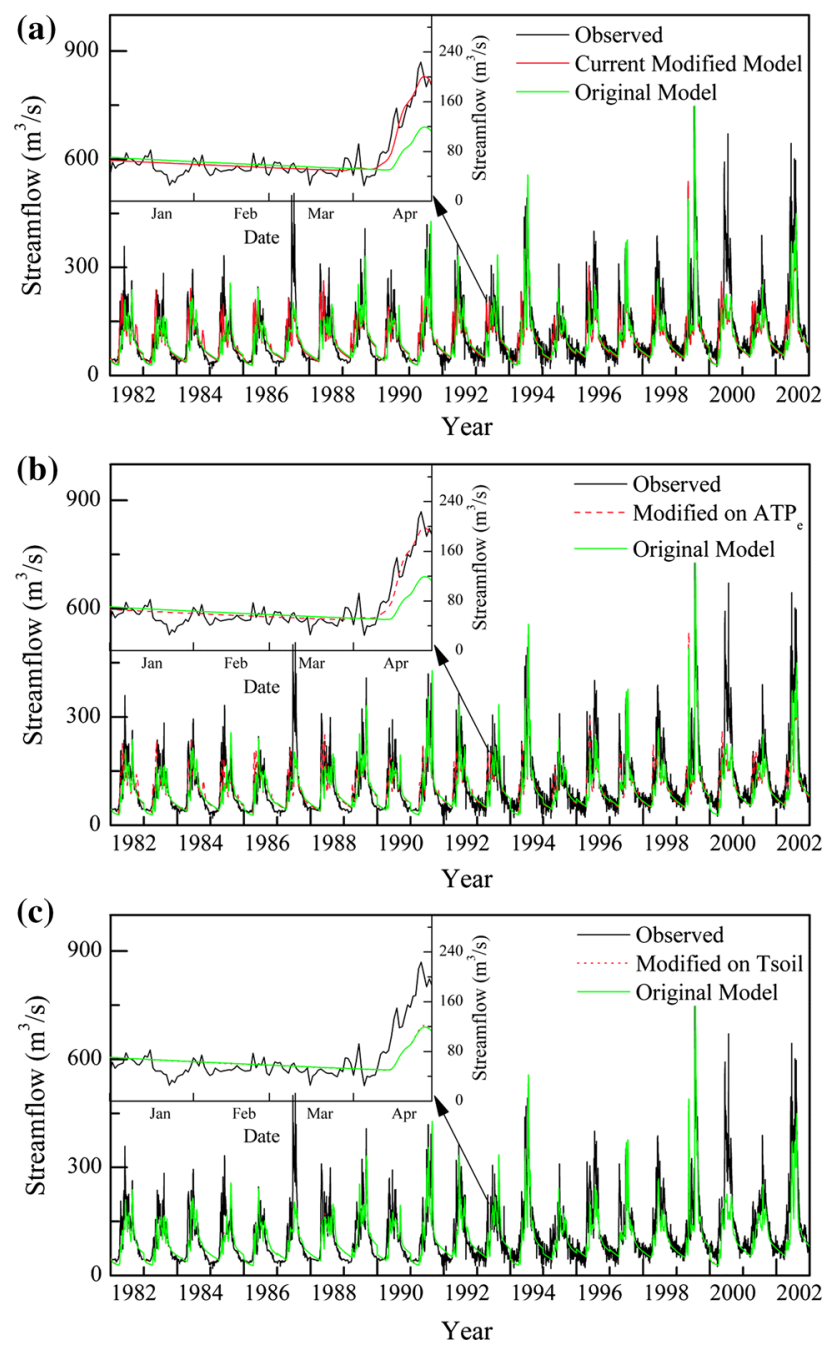

Fig. 6 The simulated streamflow from a the original model and the current modified model combined with the observed streamflow, $\mathbf{b}$ the original model and modification on $A T P_{e}$ combined with the observed streamflow, and $\mathbf{c}$ the original model and modification on $T_{\text {soil }}$ combined with the observed streamflow

factor influencing the snowmelt and infiltration processes. Floods happen in the spring due to intensive snowmelt and soil freezing, and heavy rainfall in the summer causes serious floods. In order to make full use of the water resources and prevent unpredictable damage from floods, hydrological models provide a powerful approach in understanding the formation of runoff in insufficiently gauged alpine basins. In order to reflect the snowmelt and infiltration processes that take place in the alpine basins, this study modified an existing hydrologic model-developed using system dynamics principles-in the following two ways: (1) the daily mean temperature was replaced by the $A_{T P}$ for calculating the snowmelt rate; and (2) the effects of frozen and defrosting states of various soil layers on water infiltration from the soil surface as well as
Table 6 Statistical performance of the three modified models compared to the original model

\begin{tabular}{llllll}
\hline Statistical measures & & Modified & $T_{\text {soil }}$ & $A T P_{e}$ & Original \\
\hline January to December & R & 0.78 & 0.78 & 0.78 & 0.78 \\
& NSE & 0.60 & 0.59 & 0.60 & 0.59 \\
& RSR & 0.64 & 0.64 & 0.64 & 0.64 \\
& PBIAS & 6.61 & 10.60 & 6.63 & 10.60 \\
& RMSE & 2772 & 2824 & 2772 & 2847 \\
March to May & MAE & 31.21 & 32.67 & 31.36 & 32.97 \\
& R & 0.76 & 0.59 & 0.75 & 0.58 \\
& NSE & 0.44 & 0.09 & 0.44 & 0.09 \\
& RSR & 0.75 & 0.96 & 0.75 & 0.96 \\
& PBIAS & -3.65 & 28.70 & -3.13 & 29.08 \\
& RMSE & 1985 & 3247 & 1976 & 3296 \\
& MAE & 27.99 & 38.44 & 28.01 & 38.79 \\
\hline
\end{tabular}

percolation from the upper layer were added to the model, using a soil temperature which was reconstructed by the ANN method. The streamflow in the Kaidu River basin from 1982 to 2002 was divided into three categories of streamflow: normal, high, and low flow by using the $\mathrm{Z}$ index method. The modified model was applied to simulate the three categories of streamflow. The results from the modified model demonstrated that the improvement of the number of degree-days had a great influence on the spring streamflow, while the water infiltration under the surface soil layer had only a slight influence on the streamflow.

Sensitivity analysis indicated that all the selected parameters were not sensitive to the streamflow, average streamflow, and peak flow. This indicates that the modified model was robust. Graphical and statistical comparisons between observed and simulated streamflows confirmed that the modified model could reproduce the observed streamflow well, both qualitatively and quantitatively, and was capable of capturing the essential dynamics of the spring-peak flow, summer-peak flow, and baseflow for the three categories of flows. The ability of the model to reproduce streamflow for low-flow and normal-flow years was greater than that for high-flow years. The model was capable of simulating the baseflow contributed by soil moisture and groundwater. Due to applications of the ATP $P_{e}$ to estimate the snowmelt rate and the soil temperature to reflect the soil physical state and to adjust the infiltration rate, the simulated streamflow by the modified model can well reflect the variation in the $\mathrm{ATP}_{\mathrm{e}}$ in spring, which improves the model's ability to simulate the spring- peak flow contributed by snowmelt water. The overall performance of the model indicates that the capability of the modified model to simulate the spring-peak flow contributed by snowmelt water is much better than the summerpeak flow contributed by rainfall. 
Due to the spatial heterogeneity of precipitation influenced by complex topography, vegetation, and variable elevation, it was difficult to interpolate and/or extrapolate the spatial distribution of precipitation by the commonly used linear- extrapolation method; which may have influenced the model's capability to simulate the summer-peak flows. Further studies should focus on applications of other data sources that are available, such as remote sensing data, and proper methods to interpolate and/or extrapolate the spatial distribution of precipitation in insufficiently gauged alpine basins.

Acknowledgments This work was supported by the Project of State Key Basic R\&D Program of China under Grant 973 Program, No. 2012CB956204), the National Natural Science Foundation of China (NSFC Grant No. 41401030), and the project of Xinjiang Key Laboratory of Water Cycle and Utilization in Arid Zone (Grant No. XJYS0907-2010-02). We thank Ms Linxi LI from the University of Guelph for her help in editing the manuscript.

\section{References}

Ahmad S, Simonovic S (2001) Integration of heuristic knowledge with analytical tools for selection of flood control measures. Can J Civil Eng 28(2):208-221

Apr P, Yin X (1992) Predicting water fluxes through forests from monthly precipitation and mean monthly air temperature records. Can J For Res 22(6):864-877

Bicknell B, Imhoff J, Kittle J, Donigian A (1997) Hydrological simulation program-Fortran: user's manual for version 11. U.S. Environmental Protection Agency, National Exposure Research Laboratory, Athens, Ga., EPA/600/R-97/080, 755

Blöschl G, Kirnbauer R, Gutknecht D (1990) Modelling snowmelt in a mountainous river basin on an event basis. J Hydrol 113(1):207-229

Bobba A, Lam D (1990) Hydrological modelling of acidified Canadian watersheds. Ecol Model 50(1):5-32

Campbell G (1985) Soil physics with basic: transport models for soilplant systems. Elsevier Publishing Company, Campbell

Carrier C, Kalra A, Ahmad S (2013) Using Paleo reconstructions to improve streamflow forecast lead-time in the Western United States. J Am Water Resour Assoc 49(6):1351-1366. doi:10. 1111/jawra. 12088

Choubin B, Khalighi-Sigaroodi S, Malekian A, Ahmad S, Attarod P (2014) Drought forecasting in a semi-arid watershed using climate signals: a neuro-fuzzy modeling approach. J Mt Sci 11(6):1593-1605. doi:10.1007/s11629-014-3020-6

Danish Hydraulic Institute (1992) Danish hydraulic institute reference manual, MIKE 11 DHI, Denmark

Dawadi S, Ahmad S (2012) Changing climatic condition in the Colorado River Basin: implications fr water resources management. J Hydrol. doi:10.1016/j.jhydrol.2012.02.010

Dawadi S, Ahmad S (2013) Evaluating the impact of demand-side management on water resources under changing climatic conditions and increasing population. J Environ Manag 114:261-275

Dou Y, Chen X, Bao A, Li L (2011) The simulation of snowmelt runoff in the ungauged Kaidu River Basin of Tianshan Mountains, China. Environ Earth Sci 62(5):1039-1045. doi:10.1007/ s12665-010-0592-5

Elshorbagy A, Jutla A, Barbour L, Kells J (2005) System dynamics approach to assess the sustainability of reclamation of disturbed watersheds. Can J Civil Eng 32(1):144-158. doi:10.1139/104112

Fontaine T, Cruichshank T, Arnold J, Hotchkiss R (2002) Development of a snowfall-snowmelt routine for mountainous terrain for the soil water assessment tool (SWAT). J Hydrol 262(1):209-223. doi:10.1016/S0022-1694(02)00029-X

Forsee W, Ahmad S (2011) Evaluating urban stormwater infrastructure design in response to projected climate change. J Hydrol Eng 16(11):865-873. doi:10.1061/ASCE-HE.1943-5584.0000383

Guo L, Li L (2014) Variation of the proportion of precipitation occuring as snow in the Tian Shan Mountains, China. Int J Climatol. doi:10.1002/joc.4063

Gupta H, Sorooshian S, Yapo P (1999) Status of automatic calibration for hydrologic models: comparison with multilevel expert calibration. J Hydrol Eng 4(2):135-143. doi:10.1061/ (ASCE)1084-0699(1999)4:2(135

Huang Y, Li Y, Chen X, Bao A, Ma Y (2013) A multistage simulation-based optimization model for water resources management in Tarim River Basin, China. Stoch Environ Res Risk Assess 27:147-158. doi:10.1007/s00477-012-0585-X

Ji X, Luo Y (2013) The influence of precipitation and temperature input schemes on hydrological simulations of a snow and glacier melt dominated basin in Northwest China. Hydrol Earth Syst Sci 10:807-853. doi:10.5194/hessd-10-807-2013

Jiang F, Hu R (2004) Climate change and flood \& drought disasters in Xinjiang during recent 50 years (In Chinese). J Desert Res 24(1):35-40

Kalra A, Ahmad S, Nayak A (2013) Increasing streamflow forecast lead time for snowmelt-driven catchment based on large-scale climate patterns. Adv Water Resour 53:150-162

Kite G (1998) Manual for the SLURP Hydrological Model, V. 11. National Hydrology Research Institute, Saskatoon

Kuusisto E (1984) Snow accumulation and snowmelt in Finland. Water Research Institute, Kokkola, p 55

Leavesley G, Lichty R, Troutman B, Saindon L (1983) Precipitationrunoff modeling system: user's manual. US Geological Survey Water-Resources Investigations Report 83-4238, 207

Li L, Simonovic S (2002) System dynamics model for predicting floods from snowmelt in North American prairie watersheds. Hydrol Process 16(13):2645-2666. doi:10.1002/hyp.1064

Li Y, Tan Y, Jiang F, Wang Y, Hu R (2003) Study on hydrological features of the Kaidu River and the Bosten Lake in the second half of 20th century (In Chinese). J Glaciol Geocryol 25(2):215-218

Li F, Xu Z, Liu W, Zhang Y (2014a) The impact of climate change on runoff in the Yarlung Tsangpo Rvier basin in the Tibetan Plateau. Stoch Environ Res Risk Assess 28:1577-1585. doi:10. 1007/s00477-013-0837-4

Li L, Shang M, Zhang M, Ahmad S, Huang Y (2014b) Snowmelt runoff simulation driven by aphrodite precipitation dataset (In Chinese). Adv Water Sci 25(1):53-59

Lindström G, Johansson B, Persson M, Gardelin M, Bergström S (1997) Development and test of the distributed HBV-96 hydrological model. J Hydrol 201(1):272-288. doi:10.1016/ S0022-1694(97)00041-3

Ling H, Xu H, Fu J (2013) High-and low-flow variations in annual runoff and their response to climate change in the headstreams of the Tarim River, Xinjiang, China. Hydrol Process 27:975-988. doi:10.1002/hyp.9274

Manley K (1978) Structure and stratigraphy of the Espanola Basin, Rio Grande rift, New Mexico, U.S. Geological Survey Open-File Report 78-667

Martinec J, Rango A, Roberts R (1994) The Snowmelt Runoff Model (SRM) User's Manual. Geographisches Institut der Universität

Micovic Z, Quick M (1999) A rainfall and snowmelt runoff modeling approach to flow estimation at ungauged sites in British Columbia. J Hydrol 226(1):101-120. doi:10.1016/S0022-1694(99)00172-9 
Mirchi A, Madani K, Watkins D, Ahmad S (2012) Synthesis of system dynamics tools for holistic conceptualization of water resources problems. Water Resour Manag 26(9):2421-2442

Moriasi D, Arnold J, Van Liew M, Bingner R, Harmel R, Veith T (2007) Model evaluation guidelines for systematic quantification of accuracy in watershed simulations. Trans Am Soc Agric Biol Eng 50(3):885-900

Mosquera-Machado S, Ahmad S (2007) Flood hazard assessment of Atrato river in Colombia. Water Resour Manag 21(3):591-609. doi:10.1007/s11269-006-9032-4

Nash J, Sutcliffe J (1970) River flow forecasting through conceptual models-Part 1: a discussion of principles. J Hydrol 10(3):282-290. doi:10.1016/0022-1694(70)90255-6

Puri S, Stephen H, Ahmad S (2011) Relating TRMM precipitation radar land surface backscatter response to soil moisture in the southern United States. J Hydrol 402:115-125

Qaiser K, Ahmad S, Johnson W, Batista J (2013) Evaluating water conservation and reuse policies using a dynamic water balance model. Environ Manag 51(2):449-458

Sagarika S, Kalra A, Ahmad S (2014) Evaluating the effect of persistence on long-term trends and analyzing step changes in streamflows of the continental United States. J Hydrol 517:36-53. doi:10.1016/j.jhydrol.2014.05.002

Shang M, Li L, Yao Y, Zhang F, Huang Y (2013) Analysis of factors affecting peak fow of the Kaidu river on the sourthern slope of the Tianshan Mountains (In Chinese). J Arid Land Resour Environ 27(9):85-91

Shanley J, Chalmers A (1999) The effect of frozen soil on snowmelt runoff at Sleepers River, Vermont. Hydrol Process 13:1843-1857. doi:10.1002/(SICI)1099-1085(199909)13:12/13<1843:AID-HYP $879>3.0 . \mathrm{CO} ; 2-\mathrm{G}$

Shrestha E, Ahmad S, Johnson W, Batista JR (2012) The carbon footprint of water management policy options. Energy Policy 42:201-212

Simonovic S, Ahmad S (2005) Computer-based model for flood evacuation emergency planning. Nat Hazards 34(1):25-51. doi:10.1007/s11069-004-0785-x

Stephen H, Ahmad S, Piechota T, Tang C (2010) Relating surface backscatter response from TRMM precipitation radar to soil moisture: results over a semiarid region. Hydrol Earth Syst Sci 14(2):193-204. doi:10.5194/hess-14-193-2010

Su H, Shen Y, Han P, Li J, Lan Y (2007) Precipitation and its impact on water resources and ecological environment in Xinjiang Region (In Chinese). J Glaciol Geocryol 29(3):343-350
Tao H, Wang G, Shao C, Song Y, Zou S (2007) Climate change and its effects on runoff at the headwater of Kaidu River (In Chinese). J Glaciol Geocryol 29(3):413-417

Wang J, Huang Y, Feng J, Wang B (2009) The drought monitoring in Hexi Area using the runoff-denoted $\mathrm{Z}$ index and the Palmer index (In Chinese). J Appl Meteorol Sci 20:471-476

Wu G, Li L, Ahmad S, Chen X, Pan X (2013) A dynamic model for vulnerability assessment of regional water resources in arid areas: a case study of Bayingolin, China. Water Resour Manag 27(8):3085-3101

Xu J, Chen Y, Ji M, Lu F (2008) Climate change and its effects on runoff of Kaidu River, Xinjiang, China: a multiple time-scale analysis. Chin Geogr Sci 18(4):331-339. doi:10.1007/s11769008-0331-y

Yang Q, Cui C (2005) Impact of climate change in the surface water of Kaidu River Basin. J Geogr Sci 15(1):20-28. doi:10.1007/ BF02873103

Yu M, Chen X, Li L, Bao A, Jean de la Paix M (2011) Streamflow simulation by SWAT using different precipitation sources in large arid basins with scarce raingauges. Water Resour Manag 25(11):2669-2681. doi:10.1007/s11269-011-9832-z

Yu M, Chen X, Li L, Bao A, Jean de la Paix M (2013a) Incorporating accumulated temperatue and algorithm of snow cover calculation into the snowmelt runoff model. Hydrol Process 27(25):3589-3595. doi:10.1002/hyp.9372

Yu W, Nan Z, Zhao Y, Li S (2013b) Improvement of snowmelt implementation in the SWAT hydrologic model (In Chinese). Acta Ecol Sin 33(21):6992-7001

Zhang S (1989) Flood forecasting system (In Chinese). China Water Power Press, Beijing

Zhang C, Wang B, Liu D, Cai Z (1998) Research on drought and flood indices in the Northwest China (In Chinese). Plateau Meteorol 17:382-389

Zhang Y, Li B, Bao A, Zhou C, Chen X, Zhang X (2006) Snowmelt runoff model simulation in Kaidu River Basin (In Chinese). Sci China Ser D 36(2):24-32

Zhang F, Li L, Ahmad S, Li X (2014) Using path analysis to identify the influence of climatic factors on spring peak flow dominated by snowmelt in an alpine watershed. J Mt Sci 11(4):990-1000. doi:10.1007/s11629-013-2789-z

Zhao R (1984) Watershed hydrological simulation (In Chinese). China Water Power Press, Beijing 